\title{
Consumption of Caffeinated Drink Affects Sleep Among Adults
}

Yasmin Othman Mydin ${ }^{1 *}$, Samah Ali Mohsen Mofreh ${ }^{1}$

1Universiti Sains Malaysia, School of Educational Studies

\begin{abstract}
Human spend one quarter of life in sleep. However, not everyone gets adequate sleep as there are factors that can disturb sleep that can lead to insomnia. One of the behavioural factors that can influence sleep is the consumption of caffeinated drinks. The purpose of the present study was to identify the lifestyle factor for insomnia such as consumption of caffeinated drink (tea and coffee). The participants were 500 working adults aged 20-60 years in Georgetown, Penang who were relatively healthy. The participants were recruited through convenience sampling at various working places. Athen's Insomnia Scale (AIS) was administered to screen on insomnia symptoms. 135 respondents who had insomnia symptoms were assessed on consumption of caffeinated drink in daytime and close to bedtime through descriptive questions. Interestingly, our finding showed insomnia did not increase with age, younger adults experienced more insomnia also the caffeine consumption among these adults were higher. The results revealed that consumption of caffeine in daytime and close to bedtime among young age-group significantly predicted insomnia. This finding may help to increase the awareness that sleep among young individuals can be disturbed by unhealthy lifestyle, thus it is imperative to take preventive measure against insomnia.
\end{abstract}

Keywords: Insomnia, Caffeinated Drink, Adults, Daytime, Night, Bedtime

\section{Introduction}

Sleep is a biological and behavioural phenomenon that changes in pattern across life span. There are two systems that govern the sleep-wake cycle, such as the homeostatic and circadian rhythm (Boysan, 2016). (cited from Sleep and Hypnosis Journal) The time spent in sleep may vary from one to another. There are factors that can affect sleep, which then may lead to insomnia. Approximately, over 20\% of adults in the general population experience some symptoms of insomnia (DSM-V, 2013). An epidemiology study on insomnia in Malaysia found that the prevalence

*Correspondence: dryasminothman@usm.my, +6046533888, Universiti Sains Malaysia, School of Educational Studies, 11800, Gelugur, Penang, Malaysia. Received: 13 December 2019 Accepted: 15 July 2020

\section{Sleep and Hypnosis Journal homepage: http://www.sleepandhypnosis.org} ISSN:1302-1192 (Print) 2458-9101 (Online) of insomnia symptom was $33.8 \%$ (Zailinawati, Ariff, Nurjahan \& Teng, 2008). Insomnia is not an illness but involves some symptoms. According to the fifth edition of Diagnostic and Statistical Manual of Mental Disorder (DSM-V, 2013) symptoms of insomnia are difficulty to initiate sleep, maintaining sleep, non-restorative sleep and impairment of daytime functioning.

There are several factors that can contribute to insomnia such as psychological factors, life events, physiological and behavioural aspects. Unhealthy dietary behaviour such as caffeine consumption can affect sleep among adults. Tea and coffee are caffeinated drinks that are widely consumed among adults in general population around the world. Approximately 90\% of dietary caffeine is consumed as coffee and tea (Kenny, Carlson, McGuigan, \& Sheppard, 200o). Caffeinated drink, especially coffee is one of the most widely consumed and geographically distributed stimulant drink consumed in the world (Ramakrishnan, Wesensten, 
Kamimori, Moon, Balkin \& Reifman, 2016). In Malaysia also it was found that coffee is the usual drink consumed since the pre-independent era (Amin, Rahim, Rahim \& Harun, 2016).

However, as caffeine is a stimulant and it has negative impact on individuals which one of it is sleep difficulties. It is documented that even a single cup of caffeine can interrupt sleep (Roehrs \& Roth, 2008). While excessive amount of caffeine may cause insomnia (Zastrow \& Kirst-Ashman, 2007). Shneerson (2000) proposed that a daily dose of caffeine greater than 5oomg (five cups) may cause insomnia. Drake, Roehrs, Shambroom \& Roth (2013) found that $400 \mathrm{mg}$ (four cups) of caffeine taken $\mathrm{o}, 3$, or even 6 hours before going to sleep, effects sleep significantly. Caffeine consumption in healthy individuals may include low total sleep time, difficulty to fall asleep, daytime sleepiness experienced and increased nocturnal awakenings. (Calamaro, Mason \& Ratcliffe, 2009).

Research evidences suggest that caffeine is highly consumed to keep one alert while being tired in the morning, this in turn impairs sleep quality [Snel \& Lorist, 2011; Roehrs \& Roth, 2008]. Caffeine was found to have significant negative impact on sleep.

For example, in a study in Malaysia among 2049 individuals, Zailinawati Mazza \& Teng (2012) suggested that those who drank more than five cups of caffeinated drinks had more insomnia symptoms. While, Masalamany, Ngu, Manan, \& Adam (2017) studied among 234 Malaysian university students who are young adults, reported that there was a significant association between sleep quality and caffeine intake. In light of these findings and the probability of public having lack knowledge that consumption of caffeine may contribute to insomnia, the researchers have aimed to investigate the association between caffeine intake and insomnia in Georgetown, Penang, Malaysia. To the knowledge of the researchers, there were no prior studies conducted in Penang that investigated on these variables. We find that it is imperative to study on these variables to increase the awareness in individuals on the benefit of good sleep quality and daily functioning in general population.

\section{METHOD}

\section{Participants}

The participants were adults recruited conveniently at various working places. It was a non-probability and convenience sampling. Questionnaire to screen on insomnia was distributed to 500 respondents. The inclusion criteria of participants were individuals working on normal working hours either from 8.00am or 9.00am to 5.oopm. Participants who experienced illnesses such as headache, migraine, diabetes, cardiac illnesses, hypertension, cancer and arthritis were excluded. Only generally healthy individuals were included. Out of 500 participants, 135 experienced insomnia. These insomniac individuals were investigated on caffeine consumption of either tea or coffee.

\section{Instruments}

Insomnia symptoms was measured with the use of Athens Insomnia Scale (AIS) by Soldatos (Soldatos, Dikeos \& Paparrigopoulos, 2000). AIS is a selfreport psychometric scale which consists of eight items. Five of the eight items measures symptoms of insomnia and sleep patterns such as sleep induction, awakenings at night, final awakening, total sleep duration and sleep quality.

The score of the AIS is rated on a $0-3$ scale (o corresponding to "no problem at all"; 3 to "very serious problem"). The total score ranges from 0 to 24. AIS score of six or higher indicates presence of insomnia symptoms. The reliability of this scale as reported by Soldatos, Dikeos \& Paparrigopoulos (2003) was Cronbach's alpha 0.89

\section{Descriptive Questions}

Dietary behaviour of consumption of caffeine was assessed with self-report descriptive questions. There were four questions on caffeine consumption. The participants were requested to report the practice of caffeine consumption in daytime and close to bedtime. Some of the questions were such as 'Do you consume caffeine?' 'Do you consume in daytime? How many cups do you drink in a day? Do you consume close to bedtime?'These questions were developed by referring to DSM-V (2013). Participants were categorized on 1-3 cups and 4-6 cups of caffeine 
consumption in daytime. While close to bedtime, all subjects only drank 1 cup or only 2 cups at most, thus it is categorized as 1-2 cups. This categorization was done as was suggested in past studies for example, Centers for Disease Control (2012), suggested that among military personnel, consuming more than 3 cups of caffeine was associated with less than three hours sleep. While Shilo et al., (2002) found that consumption of 5 cups in a day of coffee reduced total sleep duration significantly and caused fragmented sleep. Also a study in Malaysia found that more than 5 cups of caffeine associated with more symptoms of insomnia (Zailinawati et al., 2012). On the other hand, consumption of caffeine before going to sleep was measured on duration of time consumed 30 minutes to an hour before bedtime. This duration of time was used in past studies as having effect on sleep (Bonnet, Tancer, Uhde \&Yerangani, 2005; Drapeau, Hamel-Herbet, Robillard, Selmaoui, Filipini \& Carrier, 2006). Caffeine is available in both tea and coffee, thus in present study, those who drank either tea or coffee are taken as caffeine consumers.

\section{RESULTS}

Upon screening, 135 individuals experienced insomnia symptoms.The means of insomnia indicated that female respondents $(\mathrm{M}=4.35$; $\mathrm{SD}$ $=3.14$ ) experienced more insomnia than male respondents $(M=3.76 ; S D=3.09)$. The means of insomnia for age group 1(20-29), indicated that the youngest age group $(\mathrm{M}=4.59 ; \mathrm{SD}=3.13)$ experienced more insomnia than other age groups. The mean of insomnia of age group 4 (50-60) was the lowest.

Table 1: Frequency Distribution by Demographic Characteristics Subjects with Insomnia

\begin{tabular}{llll}
\hline Demographic profile & $\boldsymbol{N}$ & $\boldsymbol{M}$ & $\boldsymbol{S D}$ \\
\hline Gender & & & \\
\hline Male & 54 & 3.76 & 3.09 \\
\hline Female & 81 & 4.35 & 3.14 \\
\hline Age groups & & & \\
\hline $20-29$ & 64 & 4.59 & 3.13 \\
\hline $30-39$ & 38 & 4.17 & 3.22 \\
\hline $40-49$ & 24 & 3.77 & 3.13 \\
\hline $50-60$ & 9 & 2.72 & 2.25 \\
\hline
\end{tabular}

Table 1 shows the demographic of participants. Among age-groups, youngest age group consumed more caffeine in daytime, $1-3$ cups (48.5\%), 4-6 cups (36.4\%) and close to bedtime (48.8\%) compared to other age-groups. While among gender, females had more 1-3 cups (59.8\%), and males had more 4-6 cups (90.0\%) and close to bedtime (51.2\%) (Table 2).

Table 2: Caffeine Consumption by Demographic Profile Subjects with Insomnia

\begin{tabular}{llll}
\hline $\begin{array}{l}\text { Demographic } \\
\text { profile }\end{array}$ & $\begin{array}{l}\text { Caffeine1- } \\
\text { 3cups } \\
(\%) \text { In a day }\end{array}$ & $\begin{array}{l}\text { Caffeine 4-6 } \\
\text { cups } \\
\text { (\%) In a day }\end{array}$ & $\begin{array}{l}\text { Close to } \\
\text { bedtime (\%) }\end{array}$ \\
\hline Gender & & & \\
\hline Male & $39(40.2)$ & $10(90.9)$ & $21(51.2)$ \\
\hline Female & $58(59.8)$ & $1(9.1)$ & $20(48.8)$ \\
\hline Age groups & & & \\
\hline $20-29$ & $47(48.5)$ & $4(36.4)$ & $20(48.8)$ \\
\hline $30-39$ & $28(28.9)$ & $3(27.3)$ & $12(29.3)$ \\
\hline $40-49$ & $18(18.6)$ & $2(18.2)$ & $5(12.2)$ \\
\hline $50-60$ & $4(4.1)$ & $2(18.2)$ & $4(9.8)$ \\
\hline
\end{tabular}

Logistic binary regression was done to determine the effect of caffeine on insomnia among gender and age-groups. Insomnia variable was categorized according to the cut-off score of 'yes' (score 6 and above) or 'no' (a score of $0-5$ ). Independent variables were also categorized. In the regression model, when gender and caffeine intake analyzed for insomnia, the results of caffeine consumption in a day and close to bed among genders did not significantly predict insomnia, $p>$.o5. While, when age-groups and caffeine consumption in a day and close to bedtime were analyzed for insomnia, there was a positive association between caffeine intake and insomnia among youngest age-group (20-29), it significantly predicted insomnia $p$ value $<.05$. It yielded [OR: 3.225 , (95\% CI: $(1.307,8.102)]$ for daytime consumption (Table 3) and [OR: 3.221, (95\% CI: $(1.437,7.222)]$ close to bedtime (Table 4). 
Table 3: Regression Results Caffeine Consumption In a Day among Subjects with Insomnia

\begin{tabular}{llll}
\hline Demographic & $\begin{array}{l}\text { Wald } \\
\text { Statistics (df) }\end{array}$ & OR $(95 \%, \mathbf{C l}$ & $\boldsymbol{p}$ \\
\hline Gender & $2.665(1)$ & $.923(.588,1.450)$ & .728 \\
\hline Age Groups & & & \\
\hline $20-29$ & $6.431(1)$ & $3.255(1.307,8.102)$ & .011 \\
\hline $30-39$ & $3.641(1)$ & $2.503(.975,6.424)$ & .056 \\
\hline $40-49$ & $3.336(1)$ & $2.514(.500,2.125)$ & .068
\end{tabular}

Table 4: Regression Results Caffeine Consumption Close to Bedtime among Subjects with Insomnia

\begin{tabular}{llll}
\hline Demographic & $\begin{array}{l}\text { Wald } \\
\text { Statistics (df) }\end{array}$ & OR (95\%,Cl & $p$ \\
\hline Gender & $.121(1)$ & $.702(.459,1.074)$ & .103 \\
\hline Age Groups & & & \\
\hline $20-29$ & $8.065(1)$ & $3.221(1.437,7.222)$ & .005 \\
\hline $30-39$ & $3.653(1)$ & $2.266(.979,5.241)$ & .056 \\
\hline $40-49$ & $3.650(1)$ & $2.375(.978,5.766)$ & .056 \\
\hline
\end{tabular}

\section{DISCUSSION}

Caffeine's effect on sleep depends on various factors such as the dose of the caffeine consumed, the individual's tolerance to caffeine, the time consumed before going to sleep (DSM-V, 2013). In the present study, the youngest age group (2029 years) and females reported more insomnia. An interesting finding of the present study was that insomnia did not increase with age. This is in contrast to findings of previous other studies (e.g. Akerstedt, 2002; Aslan et al., 2006; Kappler \& Hohagen, 2000; Roth, 2005) which found that older adults experience more insomnia. Furthermore, higher caffeine consumption was seen in this youngest age-group. Choi (2020) found that there are several reasons for consuming tea or coffee among younger individuals, such as for the taste, to keep one alert, habitual, mood, socialization, and health benefits. The preference for coffee can be due to habitual and to increase alertness, while tea was for socialization.

The investigation on association between caffeine consumption and insomnia in present study showed that daytime and close to bedtime caffeine intake among the young age-group were positively associated that yielded significant prediction to insomnia compared to other age-groups. This means that there is a high probability of caffeine being the contributing factor to insomnia among these individuals. This is in line with the findings by Masalamany et al., (2017) that suggested young adults who had coffee everyday effected their sleep and poorer overall subjective sleep quality was also found (Kerpershoek, , Antypa \& Van den Berg, 2018). Also Nicholson and Stone (1980) found that young adults (21-31) years experienced impairment in sleep when consumed 100, 200 and 30omg of caffeine.

While the finding of caffeine consumption close to bedtime significantly predicted insomnia is similar with the finding by (Drapeau et al., 2006) and caffeine administered 30 minutes before bedtime caused great sleep difficulties (Bonnet et al., 2005). The half-life of caffeine in human ranges from 2 to 2.5 (Nehlig, 2010). This indicates that caffeine taken before bedtime remains in body system for a few hours after one goes to sleep. Caffeine is a stimulant that can cause alertness this may then disrupt the sleep pattern. The stimulant is a psychoactive substance which promotes arousal and thus causes sleep difficulties (DSM-V, 2013).

Insomniacs are typically deprived of sleep. The risk factors caused by sleep deprivation in the general population have been well reported. Unhealthy lifestyle does have an impact on sleep. Caffeine consumption and its effect on sleep may vary from one individual to another. However the stimulant in caffeine can contribute to insomnia in some individuals. There are several risks experienced by insomniacs. Most notably individuals will face problems such as daytime sleepiness, impairment in physical and mental performances and accidents. Increasing the knowledge on contributing factors to sleep difficulties may help to minimize insomnia. Cultivating healthy lifestyle of decreasing caffeine intake is one the ways to gain good sleep. Limitation of the present study is the caffeinated drink was not measured in milligram, as this may give a more accurate measurement of drink. However, individuals are only able to report consumption of caffeinated drink by the number of cups consumed.

Conflict of interest: "The authors declare no conflict of interest".

Informed consent was obtained from the respondents 


\section{References}

American Psychiatric Association. (2013). Diagnostic and statistical manual of mental disorders (5th ed.). Washington, DC.

Amin, M. Z. M., Rahim, H., Rahim, A., \& Harun, A. (2016). Persepsi dan gelagat pengguna terhadap kopi di Malaysia. Economic and Technology Management Review 11a.

Åkerstedt, T., Knutsson, A., Westerholm, P., Theorell, T., Alfredsson, L., \& Kecklund, G. (2002). Sleep disturbances, work stress and work hours: a cross-sectional study. Journal of psychosomatic research, 53(3), 741-748.

Aslan, S., Gulcat, Z., Selda Albayrak, F., Maral, I., Yetkin, S., Sutcigil, L., \& Aydin, H. (2006). Prevalence of insomnia symptoms: results from an urban d i s t ri c t i n Ankara, Turkey. International journal of psychiatry in clinical practice, $10(1), 52-58$.

Bonnet, M., Tancer, M., Uhde, T., \& Yeragani, V. K. (2005). Effects of caffeine on heart rate and QT variability during sleep. Depression and anxiety, 22(3), 150-155.

Boysan, M. (2016). Developmental implications of sleep. Sleep and Hypnosis (Online), 18(2), 44.

Calamaro, C. J., Mason, T. B., \& Ratcliffe, S. J. (2009). Adolescents living the 24/7 lifestyle: effects of caffeine and technology on sleep duration and daytime functioning. Pediatrics, 123(6), e1005-e1010.

Choi J. (2020) Motivations Influencing Caffeine Consumption Behaviors among College Students in Korea: Associations with Sleep Quality. Nutrients.;12(4):953. http://doi:10.3390/nu12040953

Centers for Disease Control and Prevention (CDC. (2012). Energy drink consumption and its association with sleep problems among US service members on a combat deploymentAfghanistan, 2010. MMWR. Morbidity and mortality weekly report, 61(44), 895 .

Drake C, Roehrs T, Shambroom J, Roth T. (2013) Caffeine effects on sleep taken 0,3 , or 6 hours before going to bed. Journal of Clinical Sleep Medicine. 9(11):1195.

Drapeau, C., HAMEL-HÉBERT, I., Robillard, R., Selmaoui, B., Filipini, D., \& Carrier, J. (2006). Challenging sleep in aging: the effects of $200 \mathrm{mg}$ of caffeine during the evening in young and middle-aged moderate caffeine consumers. Journal of sleep research, 15(2), 133-141.

Kenny, D. T., Carlson, J. G., McGuigan, F. J., Sheppard, J. L. (2000). Stress and health: Research and clinical applications. Netherlands: Harwood Academic Publishers.

Käppler, C., \& Hohagen, F. (2003). Psychosocial aspects of insomnia. European archives of psychiatry and clinical neuroscience, 253(1), 49-52.
Kerpershoek, ML, Antypa, N, Van den Berg, JF.(2018) Evening use of caffeine moderates the relationship between caffeine consumption and subjective sleep quality in students. Journal of Sleep Research. 27:e12670. https://doi.org/10.1111/jsr.12670

Masalamany, K., Ngu, S. T., Manan, N. A., \& Adam, S. K. (2017). Sleep quality among pre-clinical medical students in Universiti Putra Malaysia and Universiti Malaya, Malaysia. Education in Medicine Journal, 9(3).

Nehlig, A. (2010). Is Caffeine a Cognitive Enhancer?. Journal of Alzheimer's Disease 20. S85-S94.

Nicholson, A. N., \& Stone, B. M. (1980). Heterocyclic amphetamine derivatives and caffeine on sleep in man. British Journal of Clinical Pharmacology, 9(2), 195.

Ramakrishnan, S., Wesensten, N. J., Kamimori, G. H., Moon, J. E., Balkin, T. J., \& Reifman, J. (2016). A unified model of performance for predicting the effects of sleep and caffeine. Sleep, 39(10), 1827-1841.

Roehrs, T., \& Roth, T. (2008). Caffeine: sleep and daytime sleepiness. Sleep medicine reviews, 12(2), 153-162.

Roth, T. (2005). Prevalence, associated risks, and treatment patterns of insomnia. The Journal of clinical psychiatry, 66, 10-3.

Shneerson, J. M., (2000) Handbook of sleep medicine. London: Blackwell Science

Shilo, L., Sabbah, H., Hadari, R., Kovatz, S., Weinberg, U., Dolev, S., \& Shenkman, L. (2002). The effects of coffee consumption on sleep and melatonin secretion. Sleep medicine, 3(3), 271273.

Snel, J., \& Lorist, M. M. (2011). Effects of caffeine on sleep and cognition. In Progress in brain research (Vol. 190, pp. 105-117). Elsevier.

Soldatos, C. R., Dikeos, D. G., Paparrigopoulos, T. J. (2000). Athens Insomnia Scale: Validation of an instrument based on ICD-10 criteria. Journal of Psychosomatic Research, 48, 555-560.

Soldatos, C. R., Dikeos, D. G., Paparrigopoulos, T. J. (2003). The diagnostic validity of the Athens Insomnia Scale. Journal of Psychosomatic Research, 55, 263-267.

Zailinawati, A. H., Ariff, K. M., Nurjahan, M. I., \& Teng, C. L. (2008). Epidemiology of insomnia in Malaysian adults: a communitybased survey in 4 urban areas. Asia Pacific Journal of Public Health, 2O(3), 224-233.

Zailinawati, A. H., Mazza, D., \& Teng, C. L. (2012). Prevalence of insomnia and its impact on daily function amongst Malaysian primary care patients. Asia Pacific family medicine, 11(1), 9.

Zastrow C., \& Kirst-Ashman, K. K. (2007). Understanding human behavior and the social environment.. CA: Thomson Higher Education 